\title{
Hystera Ektomia: not always called for
}

\author{
Manvi Jindal ${ }^{1 *}$, Swati Garg ${ }^{1}$, Rachit Harjai ${ }^{2}$, Urvashi Sharma ${ }^{1}$
}

${ }^{1}$ Department of Obstetrics and Gynecology, ${ }^{2}$ Department of Radiology, Mahatma Gandhi Medical College \& Hospital, Jaipur, Rajasthan, India

Received: 27 September 2013

Accepted: 8 October 2013

\section{*Correspondence:}

Dr. Manvi Jindal,

E-mail: drmanvijindal@gmail.com

(C) 2013 Jindal M et al. This is an open-access article distributed under the terms of the Creative Commons Attribution Non-Commercial License, which permits unrestricted non-commercial use, distribution, and reproduction in any medium, provided the original work is properly cited.

\begin{abstract}
Unsympathetic hysterectomies have seen a rising trend in India in the recent times, the unsuspecting folks being pushed into surgeries wrongly citing the austerity of the illness. We highlight a case of a 26 year old female patient with post-partum bleeding per vaginum for 6 months, who was initially treated conservatively at several hospitals. Later, histopathologically proven to be a case of Choriocarcinoma (WHO Stage I with FIGO prognostic score of 5), was hysterectomized hastily overlooking the reports and the patient discharged without further intervention. Few months later the patient presented with brain and lungs metastases.

Had the patient been properly evaluated and treated appropriately initially, surgery was not indicated. Instead the patient was callously operated upon and histopathological report not followed which resulted in patient developing distant metastases (WHO Stage IV with FIGO prognostic score of 17). Unwarranted and unevaluated hysterectomies should be checked by appropriately evaluating the extent of the disease.
\end{abstract}

Keywords: Unevaluated hysterectomy, Choriocarcinoma

\section{INTRODUCTION}

Gestational trophoblastic disease (GTD) is characterized by abnormal proliferation of pregnancy-associated trophoblastic tissue with malignant potential. It encompasses a broad spectrum of conditions that includes hydatidiform mole, invasive mole, and choriocarcinoma. Treatment of trophoblastic neoplasms depends on the type and stage of the tumor and includes evacuation of the uterine contents, surgery (if the patient is not desirous of further childbearing), and chemotherapy. Callous hysterectomies, however, have become a norm in India over the past some time, the patients being misled into surgery citing severity of the disease. We highlight a case of postpartum choriocarcinoma who had an unevaluated hysterectomy without further intervention and presented few months later with multiple brain and lung metastases.

\section{CASE REPORT}

A 26 year old female patient presenting with history of bleeding per vaginum for 6 months following full term normal vaginal delivery, who was initially treated conservatively at several hospitals. Endometrial biopsy showed picture typical of choriocarcinoma (WHO Stage I with FIGO prognostic score of 5). Non-resolving symptoms and delay in diagnosis resulted in patient consulting several doctors. Hastily overlooking the reports, total abdominal hysterectomy was performed by a doctor, histopathology of which was not traced and the patient discharged without further intervention.

4 months later the patient presented to our institute with clinical symptomology pertaining to lungs (Figure 1) and brain (Figure 2) metastases which were confirmed on imaging. Laboratory investigations revealed raised serum 
b-hCG. Had the patient been properly evaluated and treated initially with evacuation and chemotherapy, surgery was not indicated. Instead the patient was callously operated upon which resulted in patient developing distant metastases (WHO Stage IV with FIGO prognostic score of 17).

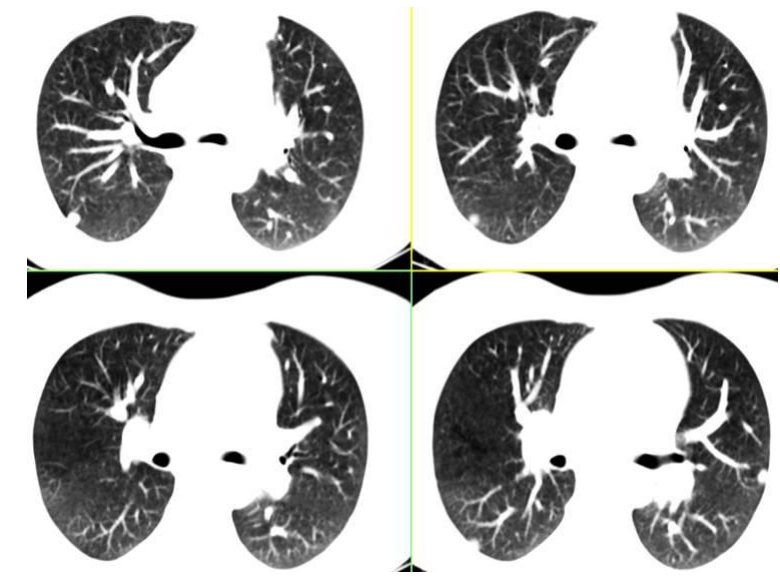

Figure 1: CT chest in lung window shows multiple subpleural nodules s/o metastasis.

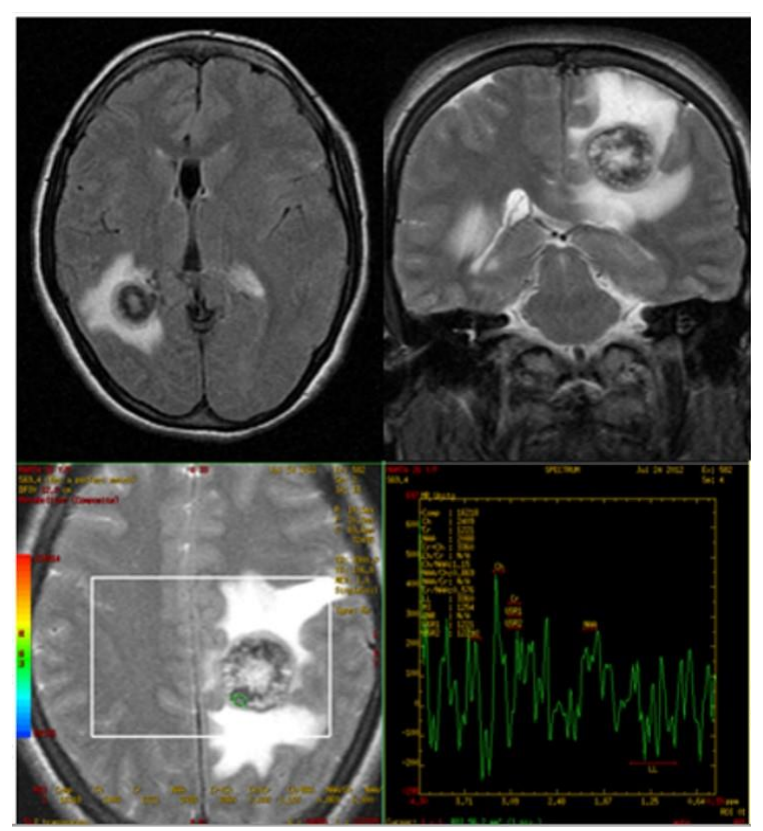

Figure 2: Axial flair and T2W coronal images show two well defined hypointense lesions in parietal regions bilaterally with raised choline and suppressed NAA peak on MR spectroscopy, findings suggestive of metastases.

\section{DISCUSSION}

3-5\% of all patients with molar pregnancies develop choriocarcinoma. Choriocarcinoma is carcinoma of the chorionic epithelium secondary to invasive growth of trophoblast and erosion of blood vessels. Amongst these, $50 \%$ develop following $\mathrm{H}$. mole, $30 \%$ following miscarriage or an ectopic pregnancy and $20 \%$ after an apparently full term normal pregnancy. Metastasis is generally blood borne because of affinity of trophoblasts for blood vessels. Majority metastasize to lungs (75\%) and vagina $(50 \%){ }^{1}$

High $\quad \beta$-hCG serum levels and positive immunohistochemistry tests for $\beta$-hCG, hPL (human placental lactogen) and $\alpha$-inhibine may be indicative of choriocarcinoma. An early and correct diagnosis of trophoblastic disease is very important due to its susceptibility to chemotherapy. Choriocarcinoma is considered the most curable gynecological cancer, even in the presence of metastatic disease, with overall survival rates of $82-100 \%$. $^{2,3}$

In the recent past, several reports of unwarranted hysterectomies have surfaced. 'The charity Oxfam has called for immediate action to stop doctors conducting unnecessary hysterectomies in Indian private healthcare facilities' - published in British Medical Journal. ${ }^{4}$ Several news media like BBC News ${ }^{5}$ and One World South Asia ${ }^{6}$ have reported similar incidences and called for regulations at such unscrulptous practice.

The National Human Rights Commission (NHRC) issued notice to the Indian state (Chhattisgarh) Chief Secretary, seeking a report on the alleged unwarranted Hysterectomy performed by unethical doctors in the state's rural areas. The NHRC move came in the wake of an expose about surgeons unnecessarily conducting the surgeries on gullible rural folk to claim money. ${ }^{7}$

An article published in 'The Week' described journey through some villages in Bihar and Rajasthan revealing the plight of women - many of them allegedly unmarriedwhose wombs were removed as "treatment" for everything, from a simple stomach ache to menstrual issues. ${ }^{8}$

Hematogenous metastasis of choriocarcinoma often occurs due to delay in the diagnosis. Early diagnosis and prompt treatment is required to prevent emotional, psychological and financial burden on the women but unwarranted and unevaluated hysterectomies should be checked. We, for the benefit of women, whose wombs are being targeted by the wolves, are trying to bring such cases to notice and support any legislation which stops this brutality on women. We suggest bringing an act to make it mandatory to report all hysterectomies to a local authority on a predesigned format mentioning symptoms, duration, alternate medical therapy given and indications for the surgery.

\section{REFERENCES}

1. Cunningham FG, MacDonald PC, Gant NF, Leveno KJ, Gilstrap LC. Diseases and abnormalities of the placenta. In: Licht J, ed. Wilhams's obstetrics. 19th ed. Norwalk, Conn: Appleton \& Lange, 1993; 748-759. 
2. Ramondetta L.M., Silva E.G., Levenback C.F., Burke T.W., Mixed choriocarcinoma in a postmenopausal patient, Int J Gynecol Cancer, 2002, 12:312-316.

3. Lurain J.R., High-risk metastatic gestational trophoblastic tumors. Current management, J Reprod Med, 1994, 39:217-222.

4. BMJ 2013; 346 doi: http://dx.doi.org/10.1136/ bmj.f852 (Published 8 February 2013).

5. Jill McGivering, The Indian women pushed into hysterectomies, 2013, Available at http://www.bbc. co.uk/news/magazine-21297606\#main-content, Accessed 20 March 2013.

6. Swapna Majumdar, Forced hysterectomies, unscrupulous doctors, 2013, Available at http:// southasia.oneworld.net/news/forced-hysterectomiesunscrupulous-doctors? searchterm=forced+hys\#. UVRP_qKwLJY, Accessed 20 March 2013.

7. Express News Service - New Delhi, NHRC notice to Chandigarh over unwarranted hysterectomies, 2012, Available at http://newindianexpress.com/ nation/article576797.ece, Accessed 27 April 2013.

8. Swagata Yadavar, Wombs and the wolves, 2013, Available at http://week.manoramaonline.com/cgibin/MMOnline.dll/portal/ep/theWeekContent.do?co ntentId=13857015\&programId=1073755753\&tabId $=13 \&$ BV_ID=\%40\%40\%40\&categoryId $=-199981$, Accessed 27 April 2013.

DOI: $10.5455 / 2320-1770 . i j r \operatorname{cog} 20131247$

Cite this article as: Jindal M, Garg S, Harjai R, Sharma U. Hystera Ektomia: not always called for. Int J Reprod Contracept Obstet Gynecol 2013;2:708-10. 